MATEC Web of Conferences 6, 01008 (2013)

DOI: $10.1051 /$ matecconf/20130601008

(C) Owned by the authors, published by EDP Sciences, 2013

\title{
Spalling of concrete: A synthesis of experimental tests on slabs
}

\author{
Nicolas Taillefer, Pierre Pimienta and Dhionis Dhima
}

Université Paris Est, CSTB, Marne la Vallée, France

\begin{abstract}
The article reviews the results of many commercial or research tests carried out in CSTB on middle size concrete slabs. They concern 22 concrete slabs, made of normal and high strength concrete, for a rather wide range of thickness and compressive strength classes. Test procedures and a synthesis of main results are presented in order to provide deeper understanding of near-reality conditions of concrete structures. The tests concerned both new and existing tunnels. Results are detailed in relation with main parameters that are identified as impacting spalling in previous studies, such as concrete composition, concrete properties and specimen size.
\end{abstract}

\section{INTRODUCTION}

When dealing with safety of structures, the assessment of fire resistance in severe thermal conditions often requires an assessment of concrete spalling. Recent catastrophic events enlightened the need for a deeper understanding on concrete mechanical characteristics changes when structures are submitted to high temperatures. On a structural point of view, spalled concrete depth is one of the essential parameters to be known, because it can directly impact the behavior of the structure. Various factors impact the physical phenomena leading to spalling and many studies aiming at better understanding them have already been undertaken. Nevertheless, there still is a demand of experimental results in order to validate models and establish proper design methods taking into account the risk of concrete spalling due to fire exposure. Several research institutes have already released experimental data to feed research, and this article is intended to be a contribution to the process.

Since 2000, French regulation for fire safety in tunnels requires tests to assess the potential impact of spalling on concrete structures [1] CSTB has made a large number of tests on different size specimen, both for research and commercial project. Since tested concrete and test configurations vary from one test to the other, many useful information and teachings could be drawn out this extended experimental feedback. A data base has been built on these tests to gather, not only test results, but also concrete properties and test configurations and then provide valuable experimental information to the community. This article deals with middle size unloaded tests on non-fibered concrete and goes through comparison and simulations to draw out some trends concerning parameters that impact spalling of concrete.

\section{TEST PROCEDURE}

All the tests presented in this paper consisted in exposing 6 middle-size $(1425 \mathrm{~mm}$ x $1250 \mathrm{~mm})$ slabs on the top of a horizontal furnace. The size of the slabs is chosen so as to prevent a too large impact of edge effect on the measures. The thermal program follows the Increased Hydrocarbon Curve, as required by

This is an Open Access article distributed under the terms of the Creative Commons Attribution License 2.0, which permits unrestricted use, distribution, and reproduction in any medium, provided the original work is properly cited. 


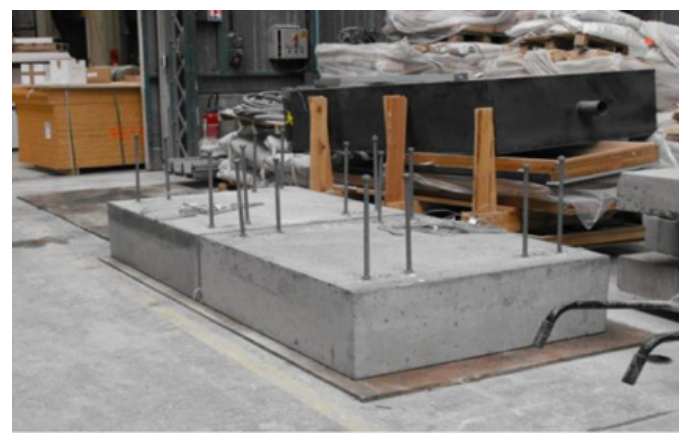

Figure 1. Two slabs cast in the laboratory.

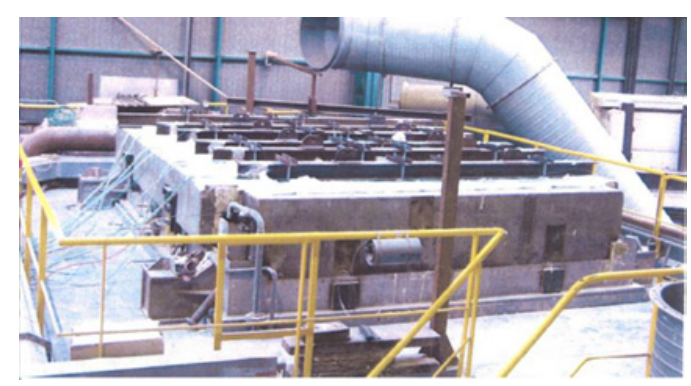

Figure 2. Six slabs tested simultaneously in the furnace.

the French regulation for tunnels. The temperature-time dependency is given by the equation (1).

$$
T\left({ }^{\circ} \mathrm{C}\right)=20+1280\left(1-0,325 e^{-0,167 t}-0,675 e^{-2,5 t}\right), \mathrm{t} \text { in }[\mathrm{min}] .
$$

Slabs are hanging on support beams, so as it can be considered that they are not mechanically loaded. Tests generally run for 2 hours, temperatures inside the slabs are measured (with a step of $15 \mathrm{~mm}$ near the exposed surface) and visual statements are made through oculi located in the walls of the furnace. Then, after the specimens have cooled down, damage concrete depth is measured, along a mesh of $150 \mathrm{~mm} \times 150 \mathrm{~mm}$.

Tests have been carried out on normal and high strength, non-fibred concrete, at least 3 month after pouring of the specimen. Any use of the test results requires insight in the material properties. Table 1 gathers the information available on the concrete composition and the slabs properties. Some slabs are cut specimens from existing tunnels, and consequently some information on the concrete is missing.

Major properties given in Table 1 are:

- type of cement and nature of aggregates;

- water/cement ratio of the mix;

- size of the slab (thickness);

- mean concrete compressive and tensile strength at the age of the test;

- mean water content of the slab at the age of the test.

\section{TEST RESULTS}

Tests results are given in Table 1. Figure 3 shows an example of a slab after test. Figure 4 shows the range of spalled concrete amount all the 18 slabs.

As it can be noticed on the picture in Figure 3, spalling observed after cooling consists in a loss of concrete near the heated surface, with a varying depth. When the damaged layer crosses the reinforcing mesh, curved pattern of damaged concrete can be seen, which implies that the mesh does not stop spalling propagation, but could influence the severity of spalling above the position of reinforcement. The picture also clearly shows that spalling differs in the centre of the slab and in the edges. It seems that, when damaged concrete layer is thick, spalling is smaller near the edges of the slab. In the contrary, when concrete is lightly damaged (for instance with polypropylene fibered concrete), edges could be adversely impacted. Figure 4 shows mean and maximum values of removed concrete cover, measured after cooling of the slabs. Since slabs are quite large (about $2 \mathrm{~m}^{2}$ ) and show a significant zone of quite homogeneous spalling, and measuring step $(15 \mathrm{~cm})$ provides about 60 usable values, authors recommend characterizing spalling by the mean value of measures. For design purpose, a characteristic 
IWCS 2013

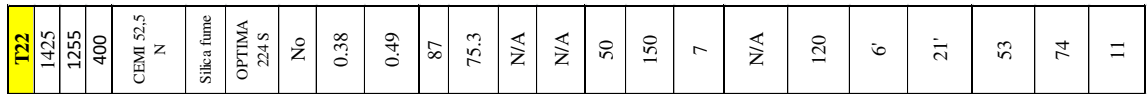

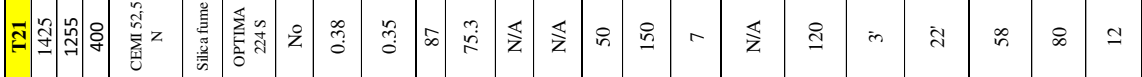

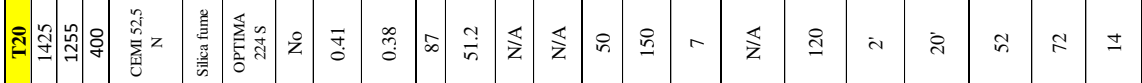

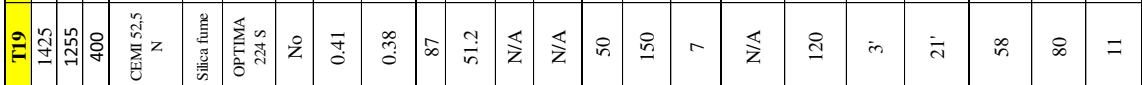

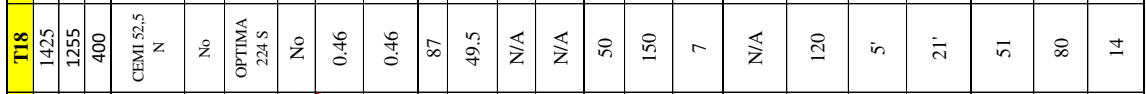

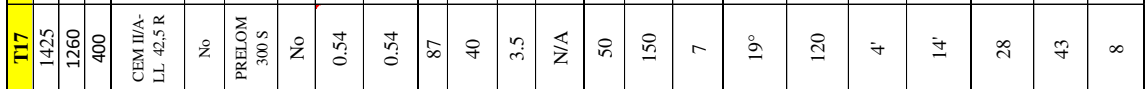

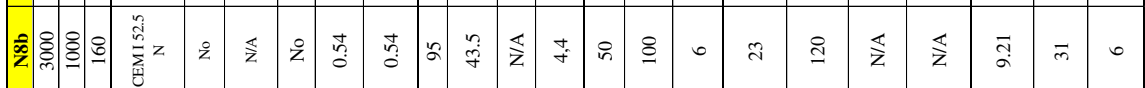

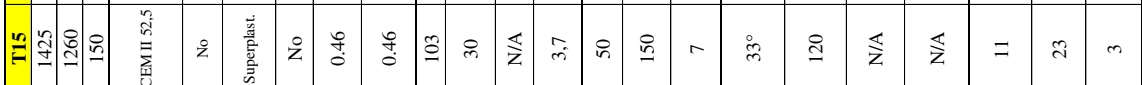

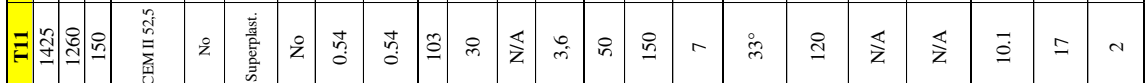

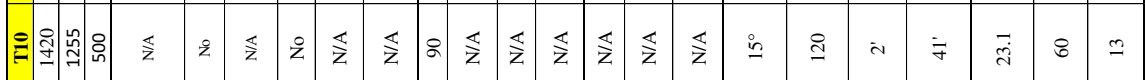

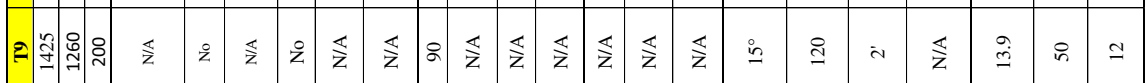

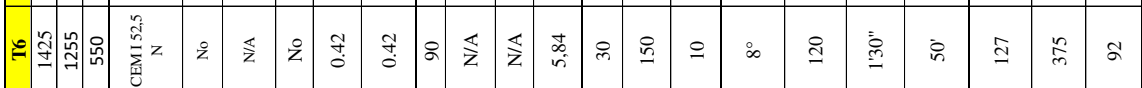

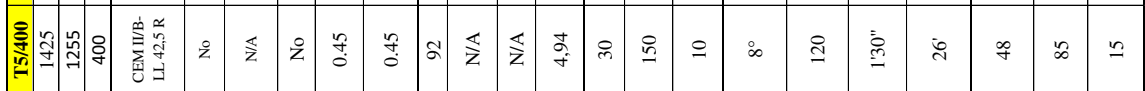

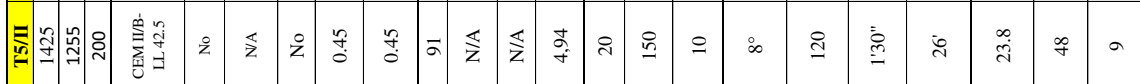

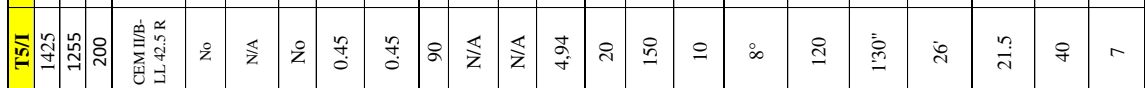

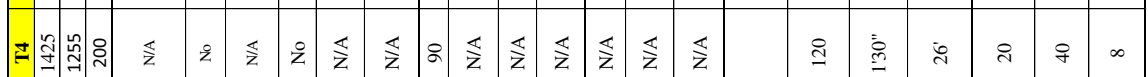

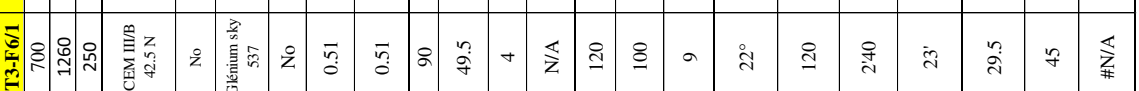

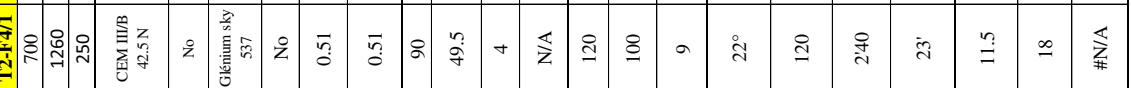

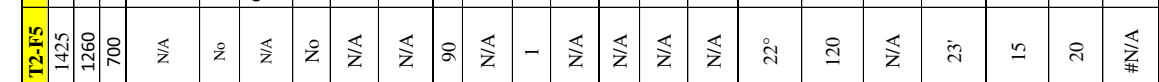

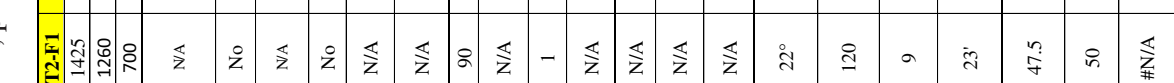

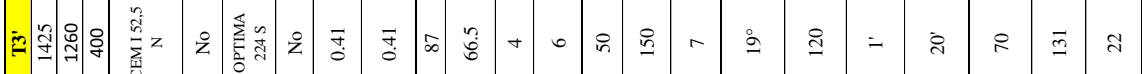

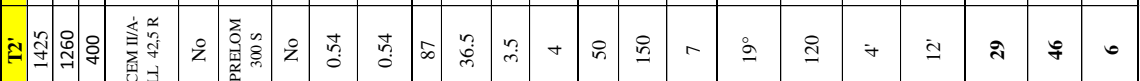

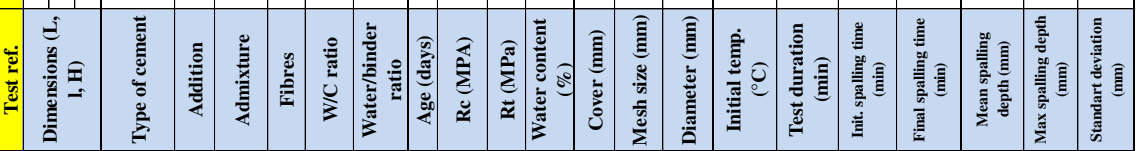




\section{MATEC Web of Conferences}

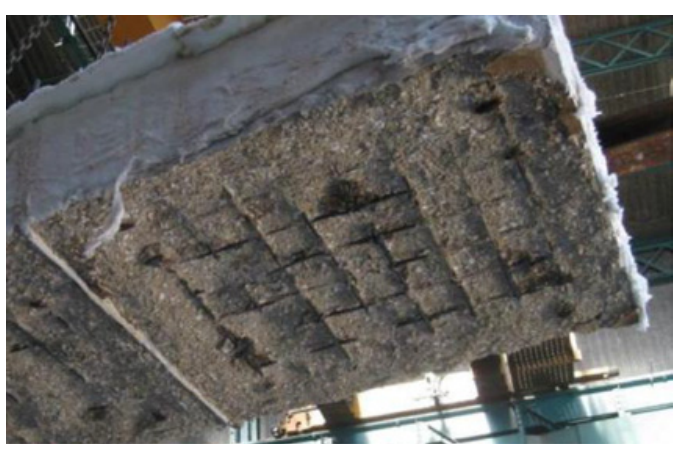

Figure 3. Example of slab after 2 hours test.

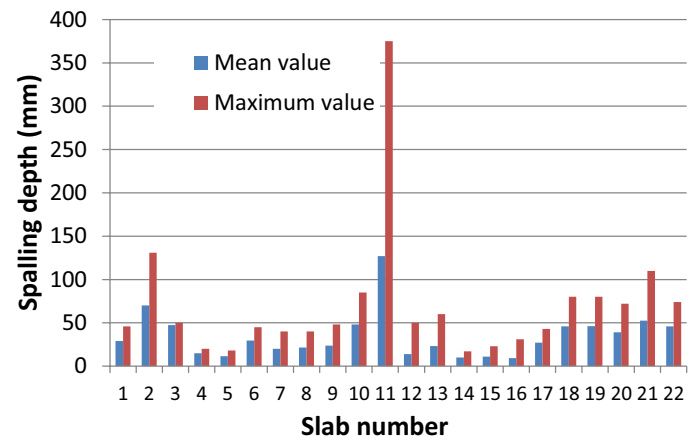

Figure 4. Mean and maximum spalling depths measured on the 18 slabs.

value should be adopted for the removed concrete depth, combining mean value and standard deviation of the measures.

Among other useful information, the time when spalling is first detected and an assessment of the duration of the phenomenon is recorded. These figures are based on rather subjective statements made during the test.

\section{DISCUSSION}

\subsection{Edge effect}

In the following, all the results on spalling are given after having neutralized edge effects, which are clearly seen on Figure 3. These effects are mainly due to stresses pattern near the edges, sometimes known as "corner effect". Results in Table 1 include mean and maximum values and standard deviation, which provide a useful assessment of the variability of the phenomenon. Damage concrete depth ranges from 10 to $120 \mathrm{~mm}$ (mean value) and variability is rather high. In many cases, spalling reaches or even goes through the reinforcing mesh.

The quantitative impact of the edge effect on the test results can be observed in Figure 7 and Figure 8. These figures present spalling depths values determined on a series of six slabs made with 3 concretes with different compressive strength. They allow comparing gross values (minimum, maximum, mean and standard deviation) and values calculated from the only measured depth inside the central zone.

When edge effect is taken into account, standard deviation decreases a little, the difference between maximum and minimum values is lower, but average spalling is larger. This is confirmed by the sight of the exposed (Fig. 5), where it can be observed that edges are less impacted than the central zone.

\subsection{Compressive strength effect}

Measured mean spalling depths versus compressive strength are plotted in Figure 9. A general trend appears in this figure. The spalling depth tends to increase when compressive strength increases. This result is in agreement with results determined on 3 concretes B40, B55 and B60 by Mindeguia [2]. It fits with the shared view by most of the researchers: high performance concrete spalling is higher than the one of normal concrete. It should be noted that several parameters are influencing concrete spalling. This a widely held view. Yet, procedures of the tests exposed in this paper differed on several points (constituents, mix proportions, thickness ...). Graphs with aligned dots are then not expected in this analyze. 


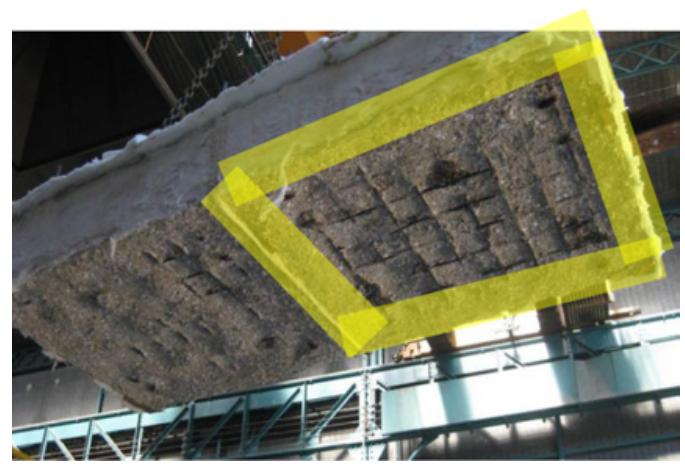

Figure 5. Zone impacted by the edge effect.

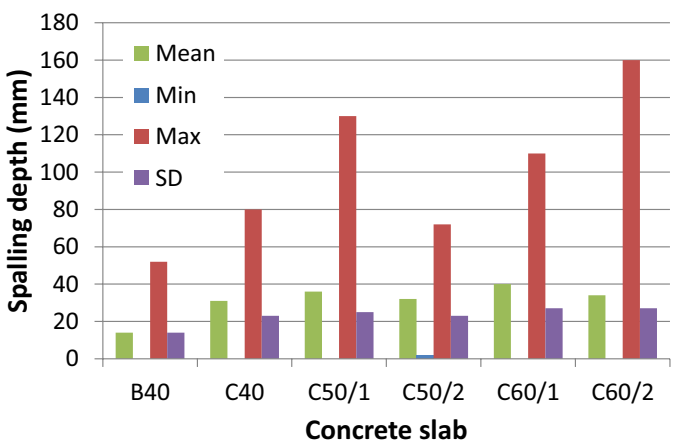

Figure 7. Spalling depth gross values (mean, minimum, maximum and standard deviation).

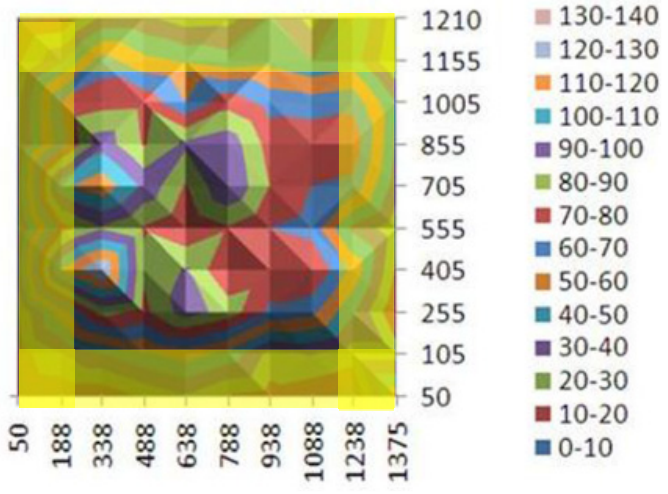

Figure 6. Zone impacted by the edge effect.

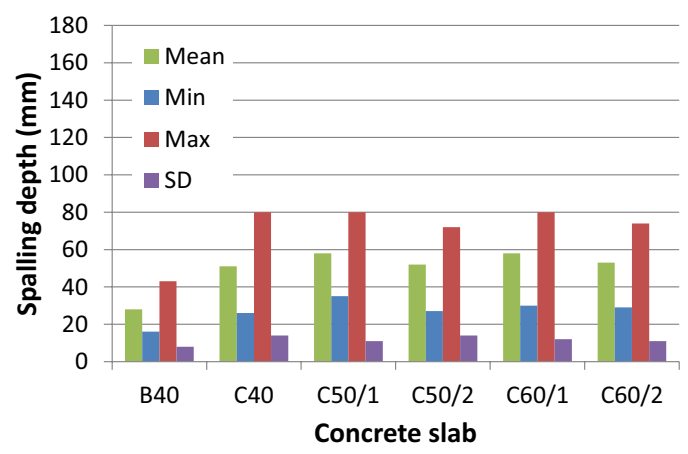

Figure 8. Spalling values inside the edge-effect free zone.

\subsection{Cement type effect}

Figure 9 allows to compare determined spalling depths results for 3 types of cements CEM I, CEM II and CEM III. Number of values is too small to conclude on a possible effect.

\subsection{Aggregates nature effect}

Figure 10 is similar to Figure 9. It allows analyzing the influence of nature of aggregates: calcareous and siliceous-calcareous. Number of values is small. However, the 3 values corresponding to silico calcareous aggregates are lower. The same trend was observed by Mindeguia [2] when exposing slabs with concrete with siliceous aggregates containing flint to ISO 834-1 temperature curve [3].

Part of the difference between measured spalling depths corresponding to the two types of aggregates is most certainly related to the loss of material during the cooling phase. Indeed, it must be pointed out that, as written before, spalling depths were measured after the test.

During the cooling phase materials can fell off the tested elements. The measure of the reduction of thickness after the test includes then every phenomenon that resulted in a loss of material whether it happened during the heating phase or during the cooling phase. During the cooling phase, loss of material can be observed.

This is particularly true when concrete are made with calcareous aggregates and are exposed during a significant time to very high temperatures as the $\mathrm{HC}_{\mathrm{inc}}$ temperature curve. When temperature is 


\section{MATEC Web of Conferences}

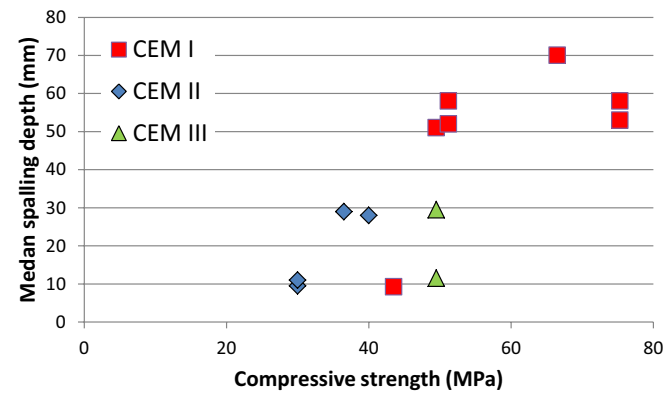

Figure 9. Effect of compressive strength and cement type.

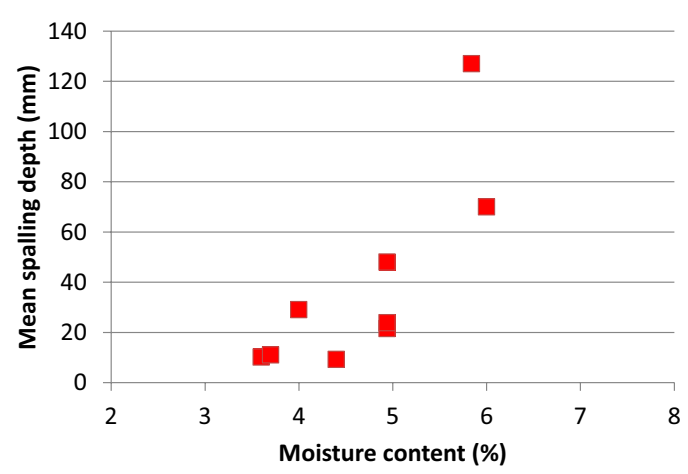

Figure 11. Effect of the moisture content.

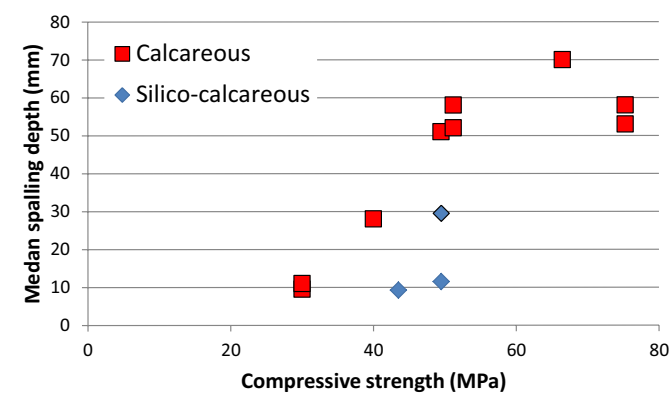

Figure 10. Effect of compressive strength and aggregates nature.

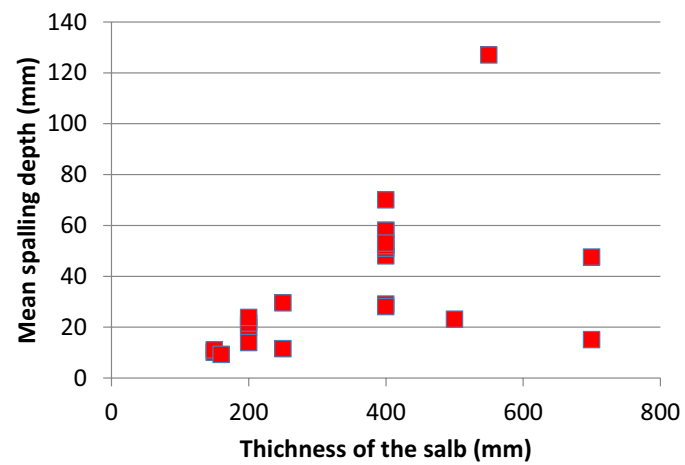

Figure 12. Effect of the thickness of the slab.

higher than $700^{\circ} \mathrm{C}$, calcium carbonate decomposition takes place. This is followed by re-hydration and carbonation during the cooling phase inducing detachment of material.

\subsection{Moisture content effect}

Water content is measured on a sample, stored in the same condition than the test specimen, at the age of the test. This corresponds to an average value other the depth of the slab. Due to drying conditions (water can mainly escape through the upper surface, the bottom one being in contact with the wood form), it is expected that a gradient in water content is still in place, since weight stability of the sample is observed. Figure 11 shows the effect of the water content. A clear correlation between moisture content and spalling depth can be seen in this Figure. This result is in quite good agreement of with results obtained by Jansson and Boström on self-compacting concrete [4]. However, these authors reported results out of this trend too.

\subsection{Thickness of the slab effect}

Section of the specimens was identical, but thickness varies. Figure 12 shows spalling results in function of the thickness.

Since slabs are not loaded, thickness potentially impacts stress distribution due to thermal non-linear gradients. On the other hand, it can also play a role in the migration of water. Results do not lead to a clear tendency for thicker slabs, since results are very scattered. This observation is certainly due to the 
IWCS 2013

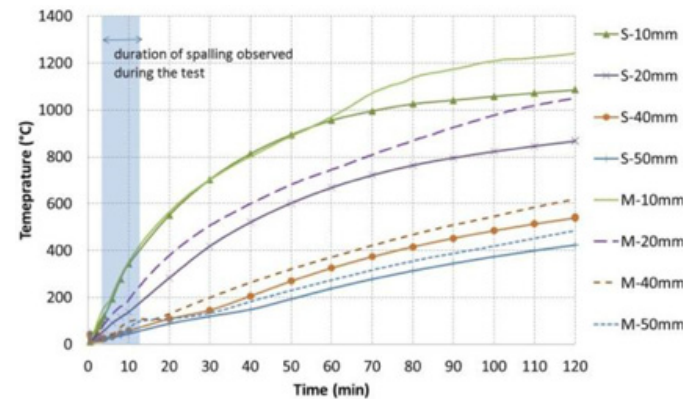

Figure 13. C40 concrete, spalling (measured mean value): $30 \mathrm{~mm}$.

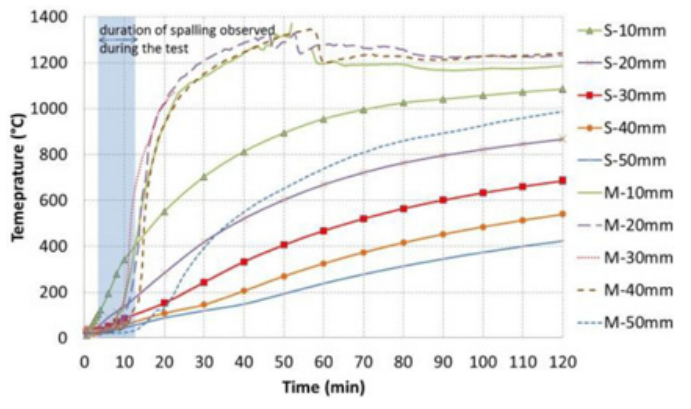

Figure 14. C40 concrete, spalling (measured mean value): $70 \mathrm{~mm}$.

fact that several phenomena are competing (water migration, mechanical strains and thermal gradients for example).

\section{ADDITIONAL SIMULATIONS OF THE TEST}

In order to provide more information on parameters which are not directly measured during the tests but could confirm or infirm some explanations of the results, simple simulations have been made on tests with the software Safir [5]. Material properties were taken directly from the Eurocodes [6], because the objective was not to calibrate a model on an experimental basis, but to complete some information.

A comparison of the measured temperature with simulated ones can provide useful information on the "effective spalling", i.e the thermal effect of the real loss of concrete during the test. As written above, effective spalling can significantly differ from concrete losses measured after cooling, and it is obviously depending of time. This is particularly true when concrete are made with calcareous aggregates and are exposed during a significant time to very high temperatures as the $\mathrm{HC}_{\mathrm{inc}}$ temperature curve.

In the first case (T'2 test, $R_{c}=36.5 \mathrm{MPa}$ ) presented in Figure 13, the impact of spalling is rather limited during fire, and fits a progressive evolution, the removed concrete depth reaching an effective value of 8 to $10 \mathrm{~mm}$. Lost concrete depth measured after cooling was $30 \mathrm{~mm}$. Records made during the test observed limited spalling of thin particles, mainly localized on small zones.

In the second case (T'3 test, $R_{c}=66.5 \mathrm{MPa}$ ) in Figure 14, thermal effect of spalling is large and impacts concrete in the $50 \mathrm{~mm}$ near the fire exposed surface. As temperatures measured with the thermocouples located at $10,20,30$ and $40 \mathrm{~mm}$ was very similar, it seems that spalling is violent and involves large concrete debris. Records of the test observed explosive spalling between $\mathrm{t}_{0}+4 \mathrm{~min}$ and $t_{0}+8$ min. Spalling was rather uniform on the fire exposed surface and reinforcement bars (cover $50 \mathrm{~mm}$ ) were visible after $14 \mathrm{~min}$. The intensity of spalling decreased after $8 \mathrm{~min}$. Temperature curves are very consistent with these observations. Explosive spalling disturbs thermocouples in the beginning of the test. $40 \mathrm{~mm}$ concrete is lost rapidly, then a slower damaging process continues. By comparing simulations and measures, "efficient spalling" can be assessed to $35 \mathrm{~mm}$, since the curve of the thermocouple located at $50 \mathrm{~mm}$ reach temperatures corresponding to $15 \mathrm{~mm}$ depth in an intact slab. In conclusion, thermal effect of spalling corresponds to a concrete loss value 15 to 20 lower than the mean value measured after cooling. It includes a lot of effects (energy consumption, shadow effect of an irregular surface....).

Comparison between simulation and measures can differentiate explosive and continuous spalling, and it provides evidences that concrete loss continues during cooling. 


\section{MATEC Web of Conferences}

\section{CONCLUSIONS}

The article deals with a rather large range of concretes, but tests were run following the same protocol, for a severe fire exposure. It appears clearly that edge effect should be taken into account properly, but the size of the slab provides an interesting zone of "uniform spalling". Since spalling involves phenomena of damaging, and potentially explosive behavior, lost concrete layer is often irregular, and depth measurements should be carried on a significant number of points. Results showed above emphasize the need to assess spalling with a mean value and a measure of the dispersion, as standard deviation.

Even if this study did not aim at identifying driving parameters of spalling, comparisons between tests confirmed the importance of the water content at the time of the test, and a clear link between concrete compressive strength and sensitivity to spalling. The thickness of the slab seems to play a role to some extent, but the dependency of spalling to both compressive strength and thickness are probably more due to a combination of factors (strains, compacity, water migration paths, ...), than to a sole parameter.

Additional investigations were made on some tests, using numerical simulation to complete tests measures. It shows very promising ways to analyze tests, such as a better assessment of the effect of spalling on concrete during the test. A simple concept of effective spalling is proposed, based on the thermal effect measured during the test. There are clear evidences that such a concept is closer to real impact of spalling than the classical concrete loss measured done after cooling of the sample. Other methods should continue to be developed latter to be able to measure losses during heating more precisely a maybe more directly.

This study is a contribution to the effort of the community to release data on spalling in test conditions, so as to favor new understanding about this phenomenon. Much work is still to be done to discover driving parameters at the scale of the material and at the scale of the structure. The complexity of the phenomena involved, and the great variety of concrete and structural configuration still require extensive tests, and an effort to synthetize the results will certainly help in providing data to models and theories developed in the future. This analyze should be combine with similar analyzes of very high heating rates temperature curve tests (as RWS) carried out in other countries.

Moreover, tests results provide key information which could be useful to improve procedures for great size fire tests in the future.

\section{References}

[1] N. Taillefer, P. Carlotti, C. Larive, C. Lemerle, R. Avenel, P. Pimienta, Ten years of increased hydrocarbon temperature curves in French tunnels. Fire Technology., April 2013.

[2] J-C. Mindeguia, Contribution expérimentale à la compréhension des risques d'instabilité thermiques du béton, $\mathrm{PhD}$, University of Pau, 2009

[3] Standard ISO 834-1 (1999) Fire-resistance tests-elements of building construction-part 1: general requirements

[4] R. Jansson, L. Boström, Factors influencing fire spalling of self compacting concrete, Materials and structures, 2013, published on line January 2013.

[5] J.M. Franssen, SAFIR user's manual, 2011

[6] NF EN (2007) 1992-1-2/NA Eurocode 2: design of concrete structures-part 1-2: general rulesstructural fire design, October 2005 and National annex to NF EN 1992-1-2:2005 - Structural fire design, October 2007 